\title{
Staged Excision of Squamous Cell Carcinoma and Actinic Keratosis of the Scalp with Staged Free Flap Inset in a Posttransplant Patient
}

\author{
Rachel Pedreira, BA ${ }^{1}$ Brian H. Cho, MD ${ }^{1}$ Arthur Nam, MD ${ }^{2}$ Paul N. Manson, MD ${ }^{1,2}$ Angela Geer, BS ${ }^{1}$ \\ Michael Grant, MD² Justin M. Sacks, MD, MBA ${ }^{1}$ Ramon A. Dejesus, MD ${ }^{1,2,3}$
}

${ }^{1}$ Department of Plastic and Reconstructive Surgery, Johns Hopkins University, Baltimore, Maryland

2 Division of Trauma Plastic Surgery, R Adams Cowley Shock Trauma Center, University of Maryland, Baltimore, Maryland

${ }^{3}$ Division of Plastic and Reconstructive Surgery, National Military

Center San Diego, San Diego, California

J Reconstr Microsurg Open 2017;2:e42-e45.

Immunosuppressive drugs are vital after solid-organ transplantation for rejection prevention but are also associated with significant complications. Malignancy as a product of immunosuppression is a common cause of posttransplant morbidity and mortality. The most common cancer in transplant patients is squamous cell carcinoma of the skin (SCCS). ${ }^{1}$ Given the rising incidence of posttransplant malignancy due to advances in perioperative care extending life expectancies, methods for addressing posttransplant SCCS merit investigation.

The scalp is one area at risk for SCCS in posttransplant patients. Scalp SCCS has a propensity for being particularly aggressive, thereby necessitating equally aggressive resection to prevent progression, metastasis, and recurrence. ${ }^{2}$ The resulting scalp defect after resection is often large and challenging to reconstruct. Rotational scalp flaps and skin grafts are effective treatment modalities; however, larger defects often require free tissue transfer for adequate soft tissue coverage. We present a unique case of recurrent SCCS of the scalp and describe a novel surgical approach.

\section{Case Presentation}

We present a 59-year-old man with recurrent scalp SCCS and a 25-year history of immunosuppression after kidney and pancreas transplant. The patient was referred to the senior author for treatment of occipital scalp SCCS that had previously been excised and reconstructed with a full-thickness skin graft (FTSG) (-Fig. 1). Because of the anticipated magnitude of the defect $(11 \times 12 \mathrm{~cm})$, surrounding actinic keratosis (AK), and compromised right superficial temporal
Address for correspondence Ramon A. Dejesus, MD, Department of Plastic and Reconstructive Surgery, Johns Hopkins University, 2012 South Tollgate Road, \#100, Bel Air, MD 21015 (e-mail: toe_2_hand@yahoo.com).

vessels from previous excisions, neither local nor rotational flaps were suitable. The patient underwent excision of the SCCS scalp lesion with negative margins. A $39 \times 12$-cm ALT flap was harvested and transferred to the scalp defect and banked for staged excision of remaining AK ( - Figs. 1, 2). The left superficial temporal vessels revealed no adequate vein; thus a saphenous vein graft was harvested and anastomosed to a branch of the external jugular vein ( - Fig. 2). Five weeks later, the free flap was elevated and defatted and further excision of AK lesions was performed. The excess-banked ALT tissue was tailored to the resultant defect and inset for definitive reconstruction (-Fig. 3). The patient recovered uneventfully and showed no complications at 6-month follow-up ( - Fig. 4). In the future, the flap can be further defatted and adjacent AK lesions excised for better contour and oncologic management.

\section{Discussion}

Cutaneous malignancy is the most common reason for scalp reconstruction ${ }^{3}$ yet the scalp has limited local options for reconstruction of considerable defects. In addition, local flap-based reconstruction may be complicated by infection, radiation, smoking, and multiple prior surgeries. ${ }^{4}$ Free flap reconstruction in the setting of these complications is advocated given the advantages of importing well-vascularized tissue into a compromised tissue bed. ${ }^{5}$

The type of flap used when local tissue cannot be advanced depends on the size and location of the defect and the state of the underlying tissue. Skin grafting for oncologic scalp defects is recommended for partial thickness or smaller received January 31, 2017 accepted after revision March 6, 2017
DOI http://dx.doi.org/ $10.1055 / \mathrm{s}-0037-1602254$. ISSN 2377-0813.
Copyright $\odot 2017$ by Thieme Medical Publishers, Inc., 333 Seventh Avenue, New York, NY 10001, USA Tel: +1(212) 584-4662.
License terms

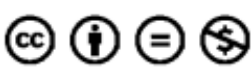



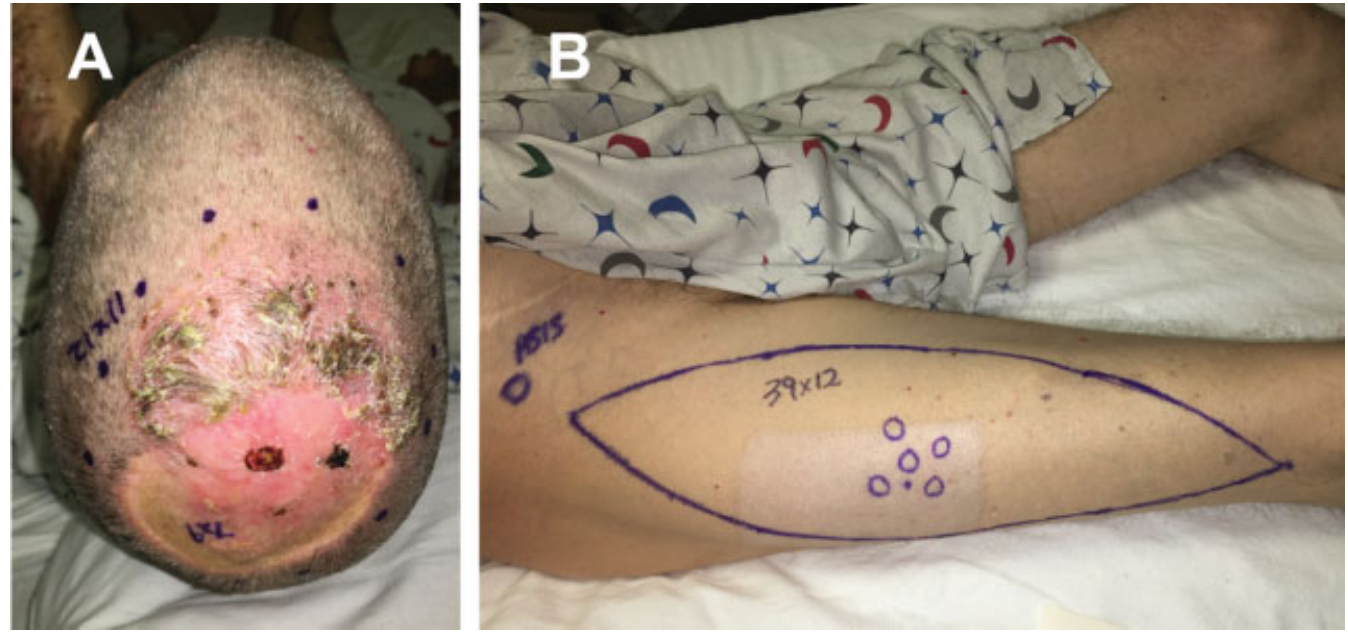

Fig. 1 Squamous cell carcinoma of scalp and preoperative free flap markings. (A) Recurrent squamous cell carcinoma of the scalp. Note previous $7 \times 9$-cm FTSG over vertex and occipital scalp. (B) Preoperative markings for right $12 \times 39-\mathrm{cm}$ right ALT flap.

scalp defects up to $8 \mathrm{~cm}$ in size. ${ }^{6}$ However, skin grafting has disadvantages; namely there is a high rate of graft loss in preradiated tissue. Thus, for larger defects or in tissue beds affected by preoperative radiation or infection, free myocu- taneous or fasciocutaneous flaps are optimal. ${ }^{7}$ Existing algorithms universally advise free flap transfer for correcting of large defects, but there is no consensus regarding which flaps are optimal for scalp reconstruction. ${ }^{6,8}$ Common flaps used
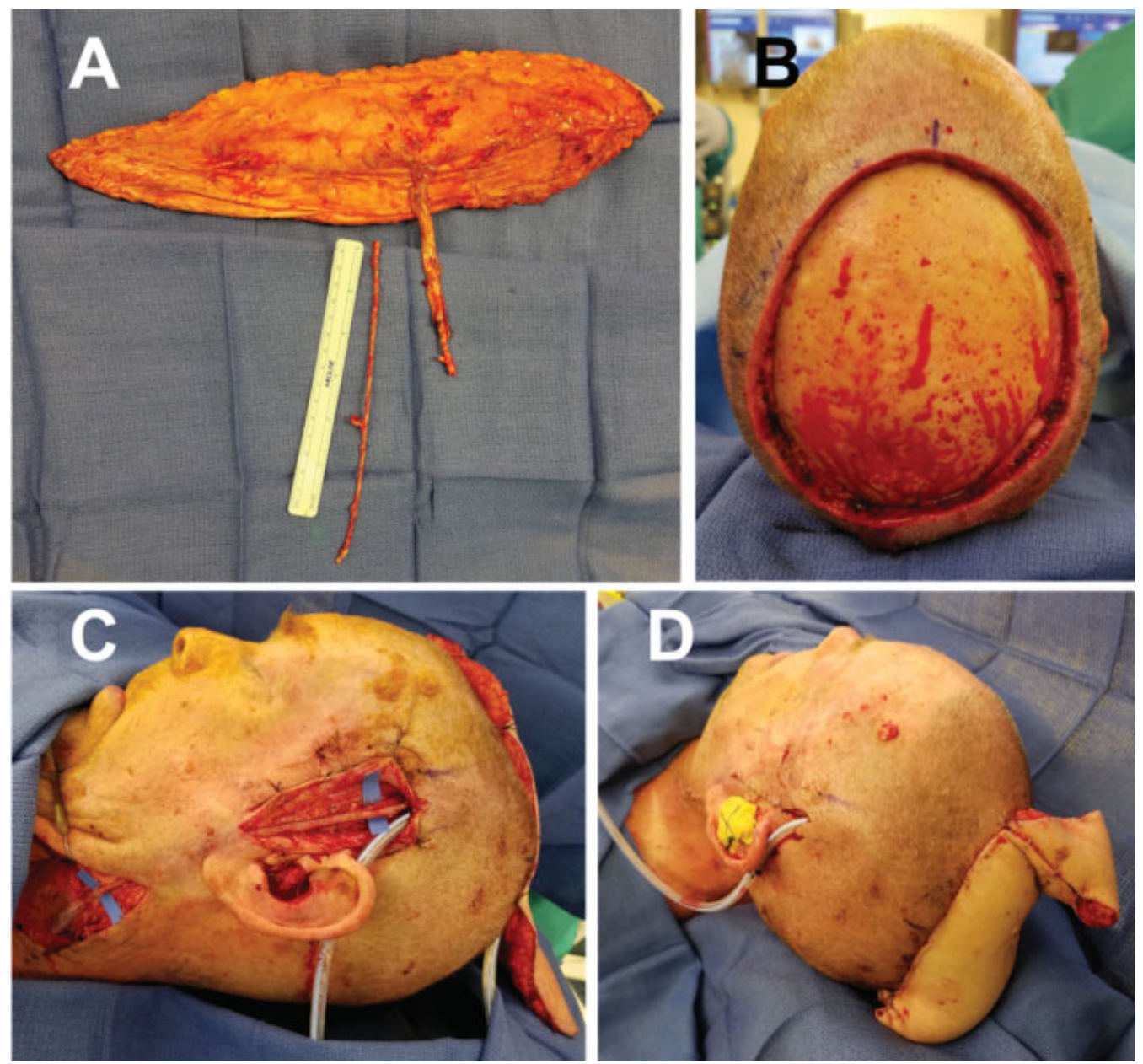

Fig. 2 First-stage excisional biopsy with initial free flap inset. (A) Harvested free ALT flap and saphenous vein graft. (B) $11 \times 12$-cm full-thickness scalp defect. (C-D) Flap inset and anastomosed to a branch of the external jugular using a saphenous vein graft. 

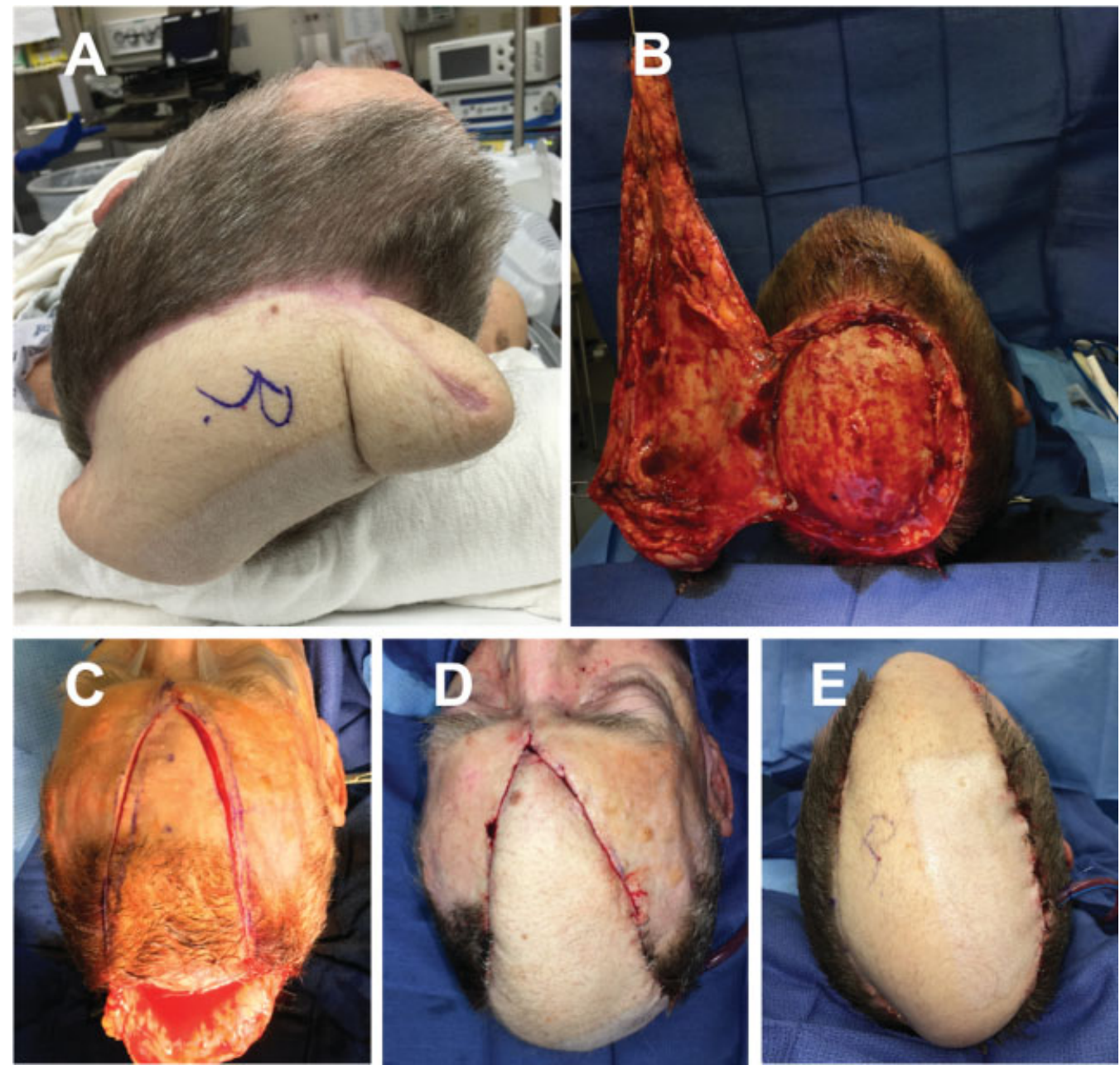

Fig. 3 Second-stage excision and flap inset. (A) Healthy ALT flap 5 weeks status post free tissue transfer. Note excess "banked" tissue for future flap inset. (B) ALT flap is elevated in preparation for further excision of premalignant lesions. (C) Resection of additional scalp and forehead AK prior to flap debulking and final inset. (D-E) Flap inset after excision of scalp and forehead lesions.
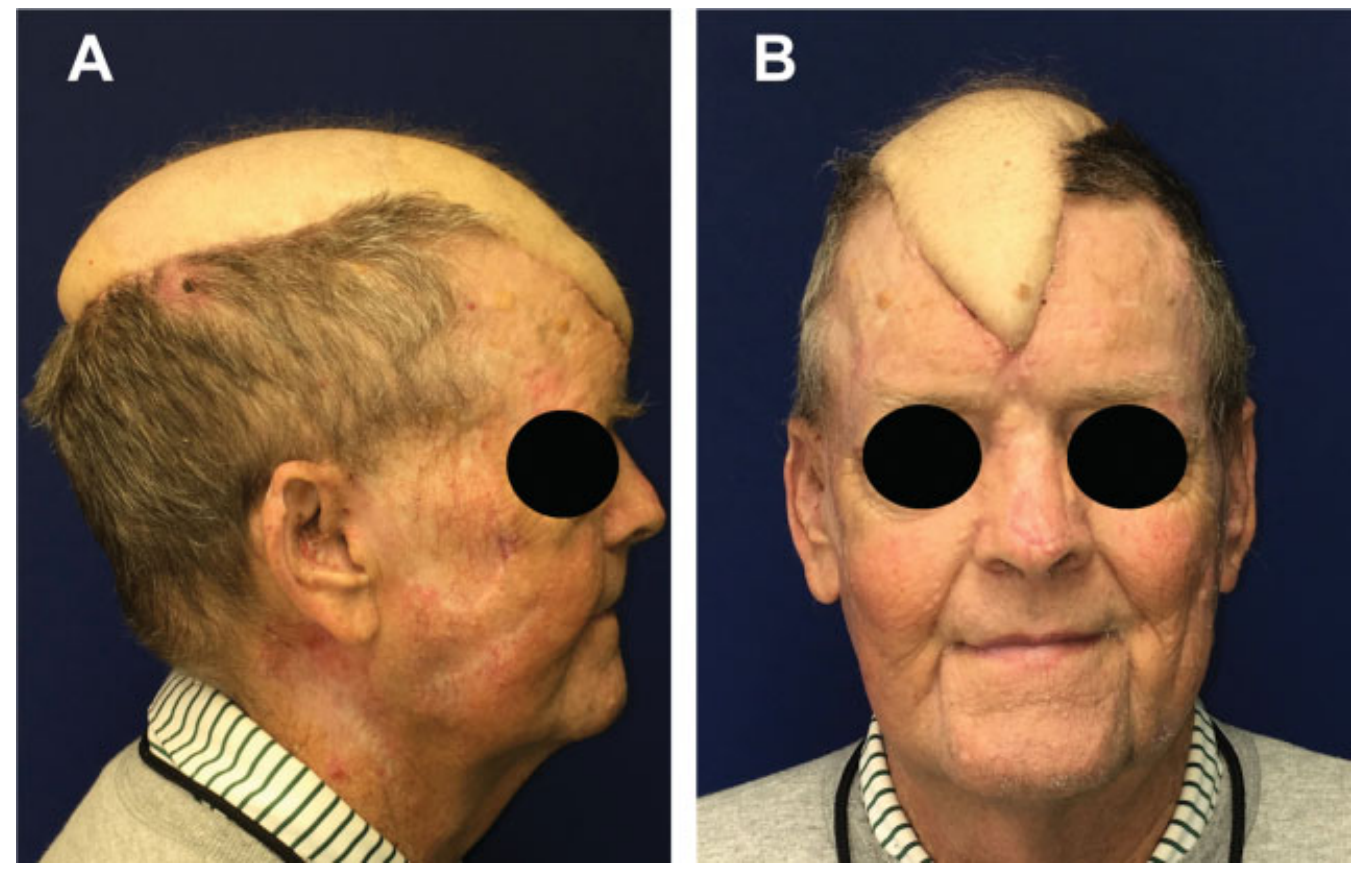

Fig. 4 Postoperative follow-up. (A-B) Scalp reconstruction with good contour at 6 months follow-up. 
include latissimus dorsi, anterolateral thigh (ALT), and rectus abdominis. However, despite published differences of opinion on the optimal flap for scalp reconstruction, the ALT flap has emerged as a popular choice given limited donor site morbidity, long reliable pedicle, and versatility. ${ }^{3}$

Cartilage and bone are frequently banked in patients to ensure tissue viability until future use; however, the concept of banking autogenous skin grafts or free tissue for future reconstruction is not widely discussed in literature. In patients undergoing unilateral mastectomy with immediate autologous reconstruction, Shridharani et al report banking contralateral DIEP flaps under abdominal closures for use in case of flap failure. ${ }^{9}$ Additionally, Jennings et al describe a forearm free flap taken from a traumatically amputated extremity, banked in the ipsilateral chest wall, and used to cover the remaining humeral stump in a subsequent surgery performed after the patient had stabilized. ${ }^{10}$ No reports of using banked tissue flaps for delayed scalp reconstruction were found in current literature.

ALT free flap for tissue "banking" with subsequent scalp and forehead excision and free flap inset was the optimal approach in the patient presented for several reasons. He experienced SCCS recurrence following FTSG reconstruction and had a large defect in the setting of numerous precancerous lesions making local reconstruction impossible. Banking tissue allowed the surgeon to establish flap viability prior to committing to further excision. By limiting the area excised-if free flap failure were to occur-the resulting defect would be smaller and more amenable to salvage. Furthermore, using an oversized banked flap allows for wide excision and potentially prevents serial flap transfers by introducing laxity into the scalp region if future local reconstruction is indicated. Finally, this technique does not compromise aesthetics in spite of neartotal reconstruction of the scalp as the banked flap is able to settle for inset when the donor tissue is less engorged.

The disadvantages to using banked tissue for scalp reconstruction include the necessity for two procedures: an initial surgery for flap inset and another for contouring. The poor aesthetics between procedures and donor site pain may also be considered disadvantageous. The limitations of this study include those associated with a single-case report.

\section{Conclusion}

In conclusion, this case report demonstrates a new perspective on surgical treatment of patients with posttransplant
SCCS with surrounding precancerous lesions requiring future surgical treatment. Ultimately, this method of reconstruction may benefit patients with a high risk of recurrence or positive margins. Furthermore, an autologous banked flap ensures donor tissue viability prior to committing to total scalp excision and increases the healthy tissue available for local reconstruction in the future. We hope the technique presented will improve the quality of life in patients with cutaneous malignancy after solid-organ transplantation.

\section{Conflict of Interest \\ None.}

\section{References}

1 Tufaro AP, Azoury SC, Crompton JG, et al. Rising incidence and aggressive nature of cutaneous malignancies after transplantation: an update on epidemiology, risk factors, management and surveillance. Surg Oncol 2015;24(04):345-352

2 Lang PG Jr, Braun MA, Kwatra R. Aggressive squamous carcinomas of the scalp. Dermatol Surg 2006;32(09):1163-1170

3 Fischer JP, Sieber B, Nelson JA, et al. A 15-year experience of complex scalp reconstruction using free tissue transfer-analysis of risk factors for complications. J Reconstr Microsurg 2013; 29(02):89-97

4 Clark JR, McCluskey SA, Hall F, et al. Predictors of morbidity following free flap reconstruction for cancer of the head and neck. Head Neck 2007;29(12):1090-1101

5 McCombe D, Donato R, Hofer SOP, Morrison W. Free flaps in the treatment of locally advanced malignancy of the scalp and forehead. Ann Plast Surg 2002;48(06):600-606

6 Iblher N, Ziegler MC, Penna V, Eisenhardt SU, Stark GB, Bannasch $\mathrm{H}$. An algorithm for oncologic scalp reconstruction. Plast Reconstr Surg 2010;126(02):450-459

7 Johnson MB, Wong AK. Integra-based reconstruction of large scalp wounds: a case report and systematic review of the literature. Plast Reconstr Surg Glob Open 2016;4(10):e1074. Doi: 10.1097/GOX.0000000000001074

8 van Driel AA, Mureau MAM, Goldstein DP, et al. Aesthetic and oncologic outcome after microsurgical reconstruction of complex scalp and forehead defects after malignant tumor resection: an algorithm for treatment. Plast Reconstr Surg 2010;126(02): 460-470

9 Shridharani SM, Singh NK, Taylor JA, Rosson GD. Banking a hemiabdominal DIEP flap: a pilot report of indications, technique, and utility. Microsurgery 2009;29(04):265-269

10 Jennings JF, Murphy RX Jr, Chernofsky MA, Chowdary RP. Amputation stump salvage using a "banked" free-tissue transfer. Ann Plast Surg 1991;27(04):361-363 